\title{
Holmium laser transurethral incision of the prostate: Can prostate size predict the long-term outcome?
}

\author{
Mohamed A. Elkoushy, MD, MSc, PhD; ${ }^{*}$ Ahmed M. Elshal, MD, FEBU, PhD; ${ }^{* \sharp}$ Mostafa M. Elhilali, MD, PhD, \\ FRCSC ${ }^{*}$
}

*Department of Surgery, Division of Urology, McGill University Health Center, Montreal, QC; * ₹epartment of Urology, Suez Canal University, Ismailia, Egypt; \#Urology and Nephrology Center, Mansoura University, Mansoura, Egypt

See related article on page 255 .

Cite as: Can Urol Assoc J 2015;9(7-8):248-54. http://dx.doi.org/10.5489/cuai.2735

Published online August 10, 2015

\section{Abstract}

Introduction: We determine the impact of prostate size on the long-term outcome of holmium laser transurethral incision of the prostate (Ho-TUIP) for bladder outlet obstruction (BOO) secondary to benign prostate enlargement (BPE).

Methods: A retrospective review of prospectively collected data was performed for patients undergoing Ho-TUIP by a single surgeon for patients presenting with lower urinary tract symptoms (LUTS) secondary to BOO. Patients were stratified into 2 groups: Group 1 included patients with prostate $\leq 30 \mathrm{cc}$ and Group 2 included patients with prostate $>30 \mathrm{cc}$. Demographic, operative and followup data were recorded and analyzed. In addition, intraoperative and long-term adverse events were included.

Results: In total, 82 patients underwent surgery between March 1998 and March 2013, including 9 (11\%) reoperated patients. Only prostate size independently predicted reoperation after Ho-TUIP (adjusted odds ratio [aOR], 95\% confidence interval [CI] 7.12 [2.92-9.14], $p=0.01$ ). The receiver operating characteristic (ROC) analysis showed an optimal cutoff value of prostate volume of 29 cc to characterize long-term reoperation after TUIP, with area under the curve (AUC) of 0.96 , sensitivity of 89.7 and specificity of 88.9. Group 1 included 51 patients and Group 2 included 31 patients. The international prostate symptoms score (IPSS) and peak flow rate (Qmax) significantly improved in both groups at different follow-up points. At the 12-month follow-up, the percent change in IPSS and Qmax were comparable between both groups. However, after 12 months, the degree of improvement in all voiding parameters was significantly higher in Group 1 ( $p<0.001$ at all points of follow-up). After a median follow-up of 5.3 years (range: $1-13$ ), both groups had comparable early and late adverse events with significantly higher reoperation rate in Group 2 (3.9\% vs. 22.6\%, $p=0.02)$. Overall retrograde ejaculation was detected in $25.6 \%$ of sexually active men and it was comparable between both groups $(23.5 \%$ vs. $29 \%, p=0.61)$. On multivariable analysis, patients with prostate volume $>30 \mathrm{cc}$ were associated with significantly higher reoperation for BOO (aOR 95\% Cl 5.72 [2.838.14], $p=0.02$ ), significantly higher IPSS (aOR 1.72), higher quality of life index (aOR 1.72) and lower Qmax (aOR 0.28).

Conclusion: Ho-TUIP is a durable, safe and efficient treatment of BOO secondary to a small-sized prostate. The long-term outcome could be improved and the re-operation rate could be minimized with appropriate selection of cases, with prostate glands no bigger than $30 \mathrm{cc}$.

\section{Introduction}

Transurethral incision of the prostate (TUIP) is a well-established treatment for bladder outlet obstruction (BOO) secondary to small-size benign prostate enlargement (BPE). The choice of TUIP was originally introduced to treat small fibrous prostates with an elevated bladder neck that became wide open after 1 or 2 incisions, without removing prostate tissue.

Systematic reviews and meta-analyses confirm that TUIP has equivalent symptomatic improvement for men with prostate glands $\pm 30 \mathrm{~mL}$, with the advantages of less morbidity, less bleeding and less sexual dysfunction than TURP. ${ }^{1,2}$ Nevertheless, TUIP is underused due to its questionable long-term efficacy and lack of data. Without considering the prostate size limit, redo TURP was needed after a mean 16 months in $23.3 \%$ of patients who underwent TUIP. ${ }^{3}$ To avoid this high failure rate, $\mathrm{Li}$ and colleagues recommended selective TURP in combination with transurethral incision of the bladder neck in patients with small obstructing prostate. ${ }^{4}$

However, in the era of laser prostatectomy, holmium laser energy is an excellent alternative to incise the prostate due its satisfactory cutting effect and superior visibility than electrocautery. Moreover, it has a minimal tissue penetration depth of $0.4 \mathrm{~mm}$, with less probability of scarring. ${ }^{5}$ Therefore, the previously mentioned adhesions between the prostatic lobes and excessive healing of the incisions, 3,6 responsible for impairment of the results after TUIP, could be avoided. 
Furthermore, there is debate about the proper management of small-size prostates. The controversy is whether to relieve the obstruction with an incision with a higher risk of reoperation for residual tissue up to $20 \%,{ }^{7}$ or to remove the adenoma with a growing evidence of increased risk of bladder neck contracture. ${ }^{8,9}$

Holmium TUIP (Ho-TUIP) has been used safely and effectively for small prostates even in high-risk anti-coagulated patients. ${ }^{7,10}$ It provides symptom reduction equivalent to that of green laser vaporization of the prostate at different follow-up points with less cost and shorter operating time, catheter time, and hospital stay. ${ }^{10}$ After Ho-TUIP, $80 \%$ of patients who needed redo procedure had prostates larger than $30 \mathrm{cc}^{7}$ Therefore, size limitations and the long-term durability of success are the main concerns. We sought to determine the impact of prostate size on the long-term outcome of holmium laser TUIP.

\section{Methods}

A retrospective review of a prospectively collected database was performed for patients undergoing Ho-TUIP for BOO secondary to BPE. All procedures were performed or supervised by a single surgeon (MME).

The decision of performing TUIP was made purely on the anatomical appearance at the preoperative cystoscopy and the wide open cavity after the initial incision. Prostate size per se was not an exclusion criterion, except for the presence of middle lobe or significant large adenoma. Therefore, even though the prostate size was measured, it was not used to select the procedure. Due to differences in outcome among patients over the long term, a post-hoc comparison was done to detect the factors which might affect the long-term outcomes of patients who underwent TUIP.

Hospital records and charts were comprehensively reviewed for perioperative and follow-up data, including demographic, operative and follow-up data. In addition, postoperative adverse events and long-term complications were recorded and analyzed.

Patients with a history of prostate surgery or history of concomitant urethral stricture were excluded (Fig. 1). Baseline and follow-up data were compared both subjectively and objectively in terms of the International Prostate Symptoms Score (IPSS), quality of life (QoL), peak flow rate (Qmax) $(\mathrm{mL} / \mathrm{sec})$, and post-void residual urine volume (PVR) $(\mathrm{mL})$. These parameters were compared at different follow-up visits at 1, 6, and 12 months and then annually. Adverse events were graded using the modified Clavien Classification System.

\section{Procedure}

We used a modified continuous flow 26Fr resectoscope, with a distal bridge to stabilize the laser fibre, continuous saline irrigation, and a video camera. Ho-TUIP was performed using a 100-Watt holmium: YAG laser (Versa Pulse Power Suite) and a 550 um end firing fibre (SlimLine 550, Inc.). The bladder neck was deeply incised at 5 and or 7 o'clock just distal to each ureteral orifice using laser energy

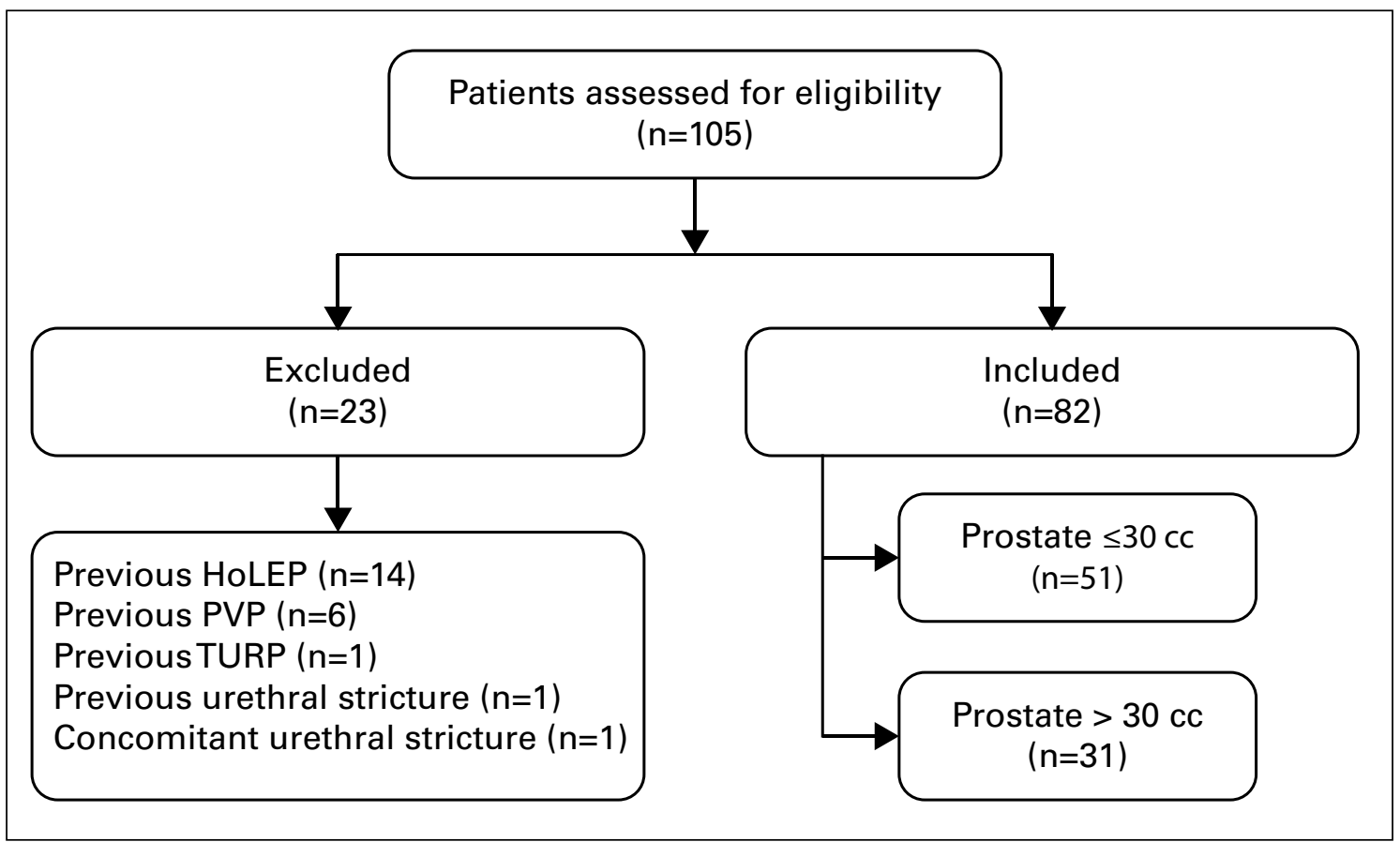

Fig. 1. Patients' enrollment and exclusions. HoLEP: Holmium laser enucleation of the prostate; PVP: Greenlight photoselective vaporization of the prostate; TURP: transurethral resection of the prostate. 
Elhilali et al.

to create a trough down to the true capsule of fat to either side of the verumontanum (laser energy of $2 \mathrm{KJ}$ and rate of $50 \mathrm{~Hz}$ ). A 2-way 22Fr Foley catheter was inserted and connected to straight drainage. The patient was discharged once the urine was clear and the patient was able to void adequately without a catheter.

\section{Statistical analysis}

Data were analyzed using Statistical Package for Social Sciences for windows, version 20 (IBMC SPSS, Armonk, $\mathrm{NY}$ ). The receiver operating characteristic (ROC) was used to determine the optimal cutoff value of prostate volume, which characterize long-term reoperation after TUIP. Descriptive statistics were presented in terms of numbers and percentages or means and standard deviations for categorical and continuous variables, respectively. Changes from baseline data for the same group were compared using the paired $t$-test while between groups comparison was done by the Fisher exact test for categorical variables and Mann Whitney- $U$ test for continuous variables. A multivariate logistic regression model was used to assess the independent effect of prostate volume on the different outcomes after adjusting for all possible perioperative parameters and reoperation for BOO. A critical two-sided $p$ value of less than 0.05 was considered statistically significant.

\section{Results}

In total, 82 patients underwent surgery between March 1998 and March 2013, including $9(11 \%)$ reoperated patients. Re-operated patients after Ho-TUIP had significantly larger prostate volume $(36.8 \pm 8.9$ vs. $27.6 \pm 5.1 \mathrm{~mL}, p<0.001)$, longer operative time, and more patients with urethral catheter than those who were not re-operated (Table 1). However, after adjusting for possible confounders in a multivariate regression model, only prostate size independently predicted re-operation after Ho-TUIP (adjusted odds ratio [aOR] 95\% confidence interval $[\mathrm{Cl}] 7.12(2.92-9.14), p=0.01)$.

The ROC analysis showed an optimal cutoff value of prostate volume of $29 \mathrm{cc}$ to characterize long-term reoperation after TUIP, with area under the curve (AUC) of 0.96, sensitivity of 89.7 and specificity of 88.9. Therefore, patients were stratified into 2 groups: Group 1 included 51 patients with prostate $\leq 30 \mathrm{cc}$ and Group 2 included 31 patients with prostate $>30 \mathrm{cc}$.

Apart from the significantly larger prostate size in Group $2(37.9 \pm 10.6$ vs. $22.6 \pm 4.9 \mathrm{~mL}, p<0.001)$, both groups were comparable in all preoperative parameters (Table 2). We also compared perioperative data and adverse events between both groups (Table 3). Postoperatively, no patient needed pharmacological therapy for BOO. However, comparable numbers of patients in Group 1 and Group 2 needed $\alpha$-adrenergic blockers during their long-term follow-up (8 [15.7\%] vs. 10 [32.3\%], $p=0.10$, respectively).

IPSS, QoL, Qmax and PVR significantly improved in both groups compared to their baseline measurements at all

\begin{tabular}{|c|c|c|c|c|}
\hline Variable & & $\begin{array}{c}\text { Non re-operated } \\
n=73\end{array}$ & $\begin{array}{c}\text { Re-operated } \\
n=9\end{array}$ & $p$ value \\
\hline \multicolumn{5}{|c|}{ Age (years $\pm S D$ ) } \\
\hline & LUTs & $64(87.7)$ & $5(55.6)$ & \multirow{3}{*}{0.03} \\
\hline \multirow[t]{2}{*}{ Presentation } & Retention & $8(11.0)$ & $4(44.4)$ & \\
\hline & Hematuria & $1(1.4)$ & $0(0)$ & \\
\hline ASA score $\geq 2$ & & $22(30.1)$ & $4(44.4)$ & 0.45 \\
\hline \multicolumn{2}{|c|}{ Preoperative prostate medications } & $47(64.4)$ & $6(66.7)$ & 1.00 \\
\hline \multicolumn{2}{|c|}{ Patients with diabetes mellitus } & $10(13.4)$ & $2(22.2)$ & 0.61 \\
\hline \multicolumn{2}{|c|}{ Preoperative anticoagulants } & $7(9.5)$ & $2(22.2)$ & 0.26 \\
\hline \multicolumn{2}{|c|}{ Preoperative IPSS } & $17.2 \pm 5.4$ & $16.8 \pm 6.3$ & 0.84 \\
\hline \multicolumn{2}{|c|}{ Preoperative QoL } & $3.2 \pm 1.3$ & $3.4 \pm 1.2$ & 0.66 \\
\hline \multicolumn{2}{|c|}{ Preoperative Omax } & $8.2 \pm 3.4$ & $7.6 \pm 2.8$ & 0.21 \\
\hline \multicolumn{2}{|c|}{ Preoperative PVR } & $122.6 \pm 68$ & $102 \pm 74$ & 0.40 \\
\hline \multicolumn{2}{|c|}{ Mean PSA (ng/mL \pm SD) } & $2.8 \pm 4.2$ & $3.8 \pm 6.4$ & 0.53 \\
\hline \multicolumn{2}{|c|}{ Mean TRUS volume of the gland $(\mathrm{mL} \pm \mathrm{SD})$} & $27.6 \pm 5.1$ & $36.8 \pm 8.9$ & $<0.001$ \\
\hline \multicolumn{2}{|c|}{ Mean operative time (min) } & $25.8 \pm 14.7$ & $38.2 \pm 28.9$ & 0.04 \\
\hline \multicolumn{2}{|c|}{ Mean energy utilized $(\mathrm{KJ} \pm \mathrm{SD}$ ) } & $49.4 \pm 28.9$ & $68.7 \pm 34.3$ & 0.06 \\
\hline \multicolumn{2}{|c|}{ Mean catheterization time (days \pm SD) } & $1.3 \pm 2.1$ & $1.8 \pm 1.9$ & 0.49 \\
\hline \multicolumn{2}{|c|}{ Mean hospital stay (days \pm SD) } & $0.92 \pm 0.32$ & $1.1 \pm 0.46$ & 0.17 \\
\hline
\end{tabular}




\begin{tabular}{|c|c|c|c|c|}
\hline \multicolumn{2}{|l|}{ Variable } & $\begin{array}{c}\text { Group I } \\
\text { Prostate } \leq 30 \mathrm{cc} \\
\mathrm{n}=51\end{array}$ & $\begin{array}{c}\text { Group II } \\
\text { Prostate }>30 \text { cc } \\
n=31\end{array}$ & $p$ value \\
\hline \multicolumn{2}{|l|}{ Age (years +SD) } & $72.5 \pm 17$ & $73.3 \pm 8$ & \\
\hline Indications for surgery & $\begin{array}{l}\text { LUTs } \\
\text { Retention } \\
\text { Hematuria }\end{array}$ & $\begin{aligned} 46 & (90.2) \\
4 & (7.8) \\
1 & (2.0)\end{aligned}$ & $\begin{array}{c}23(74.2) \\
8(25.8) \\
0(0)\end{array}$ & 0.49 \\
\hline ASA score & $\begin{array}{l}\text { I } \\
\text { II } \\
\text { III }\end{array}$ & $\begin{array}{l}35(68.6) \\
10(19.6) \\
6(11.8)\end{array}$ & $\begin{array}{c}21(67.7) \\
9(29.0) \\
1(3.2)\end{array}$ & 0.60 \\
\hline $\begin{array}{l}\text { Preoperative prostate } \\
\text { medications }\end{array}$ & $\begin{array}{l}\text { None } \\
\text { Alpha blockers } \\
\text { Combination therapy }\end{array}$ & $\begin{aligned} 19 & (37.3) \\
30 & (58.8) \\
2 & (3.9)\end{aligned}$ & $\begin{array}{c}10(32.2) \\
19(61.3) \\
2(6.5)\end{array}$ & 0.82 \\
\hline Concomitant procedures & $\begin{array}{l}\text { None } \\
\text { Cystolitholapaxy } \\
\text { Bladder biopsy/tumour resection }\end{array}$ & $\begin{aligned} 47 & (92.2) \\
2 & (3.9) \\
2 & (3.9)\end{aligned}$ & $\begin{array}{l}25(80.6) \\
5(16.1) \\
1(3.2)\end{array}$ & 0.27 \\
\hline \multicolumn{2}{|l|}{ Diabetes mellitus } & $6(11.8)$ & $6(19.4)$ & 0.36 \\
\hline \multicolumn{2}{|l|}{ Preoperative anticoagulants } & $4(7.8)$ & $5(16.1)$ & 0.29 \\
\hline \multicolumn{2}{|l|}{ Preoperative IPSS } & $16.0 \pm 6.2$ & $16.4 \pm 6.8$ & 0.84 \\
\hline \multicolumn{2}{|l|}{ Preoperative QOL } & $3.4 \pm 1.2$ & $3.3 \pm 1.1$ & 0.64 \\
\hline \multicolumn{2}{|l|}{ Preoperative Qmax } & $8.1 \pm 3.9$ & $7.9 \pm 3.8$ & 0.96 \\
\hline \multicolumn{2}{|l|}{ Preoperative PVR } & $118.6 \pm 139$ & $92.9 \pm 149$ & 0.66 \\
\hline \multicolumn{2}{|c|}{ Mean PSA $(n g / m L \pm S D)$} & $2.6 \pm 4.6$ & $3.8 \pm 7.9$ & 0.45 \\
\hline \multicolumn{2}{|c|}{ Mean TRUS volume of the gland $(\mathrm{mL} \pm \mathrm{SD})$} & $22.6 \pm 4.9$ & $37.9 \pm 10.6$ & $<0.001$ \\
\hline
\end{tabular}

follow-up visits (Fig. 2). Similarly, both groups were comparable in subjective and objective voiding parameters within the first 12 months postoperatively. The percent changes in IPSS and QoL were $63.7 \%$ vs. $61.6 \%, \mathrm{p}=0.83$ and $55.9 \%$ vs. $42.8 \%, p=0.11$ in Groups 1 and 2, respectively. The percent changes in Qmax and PVR were $118.5 \%$ vs. 100\%, $p=0.62$ and $46.2 \%$ vs. $28 \%, p=0.08$ in Groups 1 and 2, respectively (Fig. 2).

However, after 12 months follow-up, the degree of improvement in all voiding parameters was significantly higher in patients undergoing TUIP for prostate $\leq 30 \mathrm{cc}$ compared to those with larger prostates $(p<0.001$ at all periods

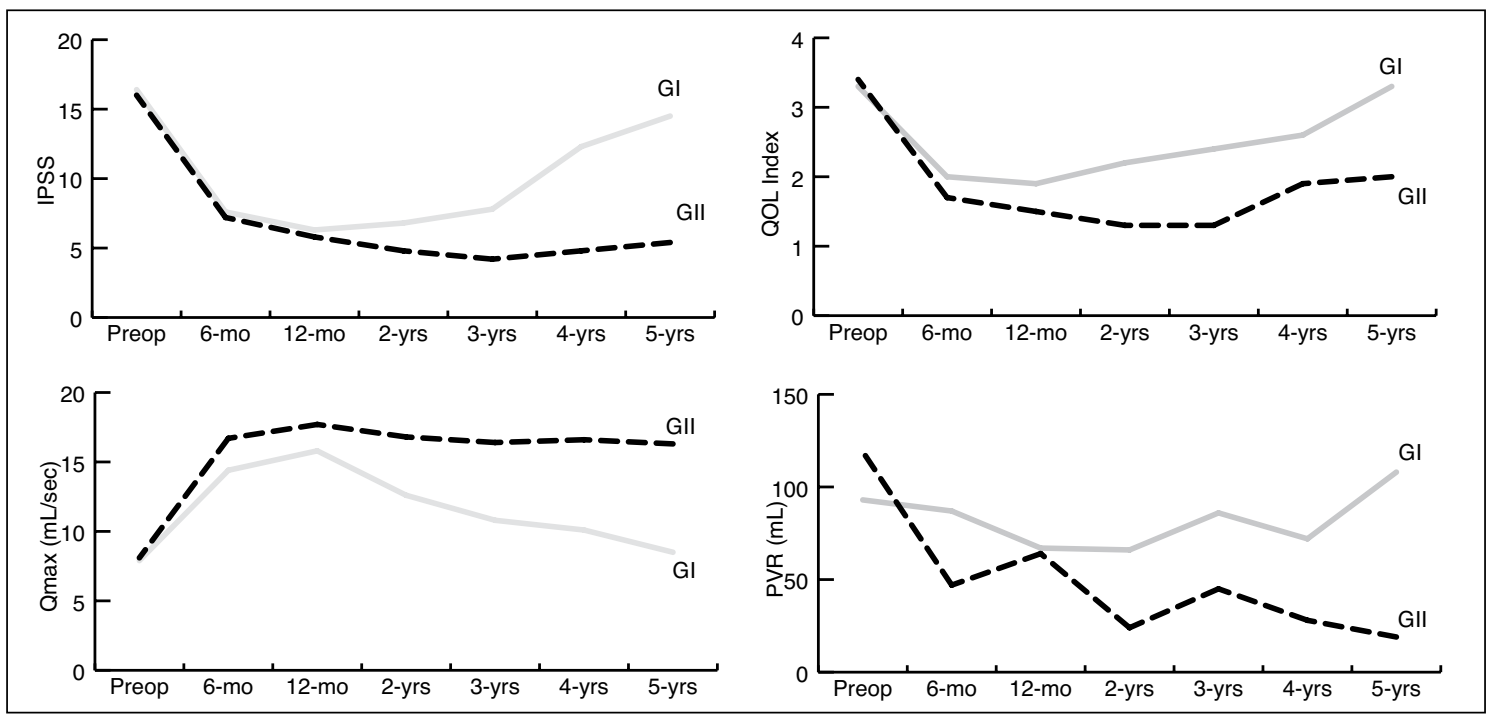

Fig. 2. Outcome parameters and number of evaluable patients who underwent Holmium TUIP for both groups at different follow-up points. ${ }^{*} p<0.001$. IPSS: International Prostate Symptoms Score; TUIP: transurethral incision of the prostate; OoL: quality of life; Qmax: peak flow rate; PVR: post-void residual urine volume. 
Elhilali et al.

\begin{tabular}{|c|c|c|c|c|}
\hline \multicolumn{2}{|l|}{ Variable } & Group $1 \mathrm{n}=53$ & Group 2 n= 31 & $p$ value \\
\hline \multicolumn{2}{|c|}{ Mean operative time (min) } & $26.1 \pm 16.6$ & $37.6 \pm 33.0$ & 0.16 \\
\hline \multicolumn{2}{|c|}{ Mean energy utilized $(\mathrm{KJ} \pm \mathrm{SD})$} & $50.3 \pm 26.1$ & $61.2 \pm 38.3$ & 0.18 \\
\hline \multicolumn{2}{|c|}{ Mean catheterization time (days \pm SD) } & $1.7 \pm 2.8$ & $2.2 \pm 3.9$ & 0.71 \\
\hline \multicolumn{2}{|c|}{ Mean hospital stay (days \pm SD) } & $0.86 \pm 0.34$ & $0.89 \pm 0.33$ & 0.82 \\
\hline \multicolumn{2}{|c|}{ Failed trial of voiding/early retention } & $0(0)$ & 1 & 0.34 \\
\hline \multicolumn{5}{|c|}{ Postoperative complications } \\
\hline \multirow{3}{*}{ Low grade Clavien I-II } & Failed TOV & $1(2.0)$ & $0(0)$ & \\
\hline & Retrograde ejaculation & $15(29.4)$ & $11(35.5)$ & \\
\hline & Recurrent UTI & 2 (3.9) & $1(3.2)$ & 0.11 \\
\hline \multirow{2}{*}{ High grade Clavien $\geq$ III } & Reoperation for $\mathrm{BOO}$ & $2(3.8)$ & $7(22.6)$ & \\
\hline & Urethral stricture & $1(1.9)$ & $1(3.2)$ & \\
\hline
\end{tabular}

SD: standard deviation; TOV: trial of voiding; UTI: urinary tract infection; BOO: bladder outlet obstruction.

of follow-up) (Fig. 2). After a median follow-up of 5.3 years (range: 1-13), Group 1 patients had more improvement in the percent change of IPSS $(59.3 \%$ vs. $14 \%, p=0.03)$ and Qmax (65\% vs. 17\%, $p=0.02)$ than Group 2 patients, respectively. The overall percent change in QoL was $41.2 \%$ in Group 1 patients, while the QoL of those operated for prostate volume $>30 \mathrm{cc}$ showed a $10 \%$ deterioration than its baseline values (Fig. 3).

Both groups were comparable in terms of early and late adverse events (Table 2). Only 1 patient in Group 2 failed to void adequately after catheter removal. Postoperative urine incontinence was not reported by any patient.

Overall reoperation rate was $11 \%$, which was significantly higher in Group 2 (3.9\% vs. $22.6 \%, p=0.02)$. Two patients in Group 1 (3.9\%) were re-operated: 1 patient developed urethral strictures after 13 months and the other

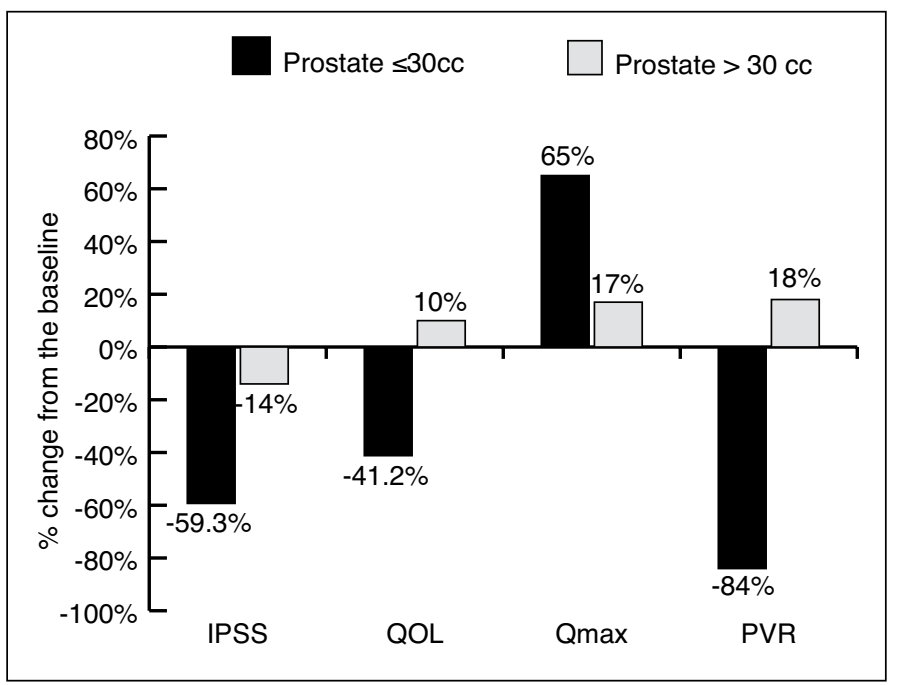

Fig. 3. Percent reduction of IPSS, $\mathrm{O}_{\mathrm{L}} \mathrm{L}$ and $\mathrm{Qmax}$ at the most recent follow-up in patients undergoing Holmium TUIP for prostate $\leq 30 \mathrm{cc}$ or larger than $30 \mathrm{cc}$. IPSS: International Prostate Symptoms Score; QoL: quality of life; Omax: peak flow rate; PVR: post-void residual urine volume. patient needed holmium laser enucleation of the prostate (HoLEP) for progression of adenoma after 9 years follow-up. Seven patients in Group 2 (22.6\%) needed reoperation: 1 developed urethral stricture after 15 months, and 6 required re-operation for recurrent bothersome lower urinary tract symptoms (LUTS). Of these 6 patients, 2 underwent HoLEP after 2 and 4 years post-TUIP, 3 patients needed a second green light HPS photoselective vaporization of the prostate after a mean follow-up of 18 months, and the last patient needed a second bladder neck incision after 9 months. Overall retrograde ejaculation was detected in $25.6 \%$ of sexually active men and it was comparable between groups $(23.5 \%$ vs. $29 \%, p=0.61)$.

After correcting for possible confounders on multivariable analysis, we associated patients with prostate volume $>30$ cc with significantly higher re-operation for BOO (aOR 95\% Cl 5.72 [2.83-8.14], $p=0.02$ ), significantly higher IPSS (aOR 1.72 [1.37-1.94], $p<0.001$ ), higher QoL index (aOR 1.72 [1.37-1.94], $p<0.001$ ) and lower Qmax (aOR 0.28 [0.16-0.42], $p<0.001$ ).

\section{Discussion}

Ho-TUIP is a feasible, minimally invasive outpatient procedure in patients with small prostates. It is faster than HoLEP with equivalent functional outcomes and lower rates of early stress urinary incontinence. ${ }^{7}$ However, there is no data which characterize those patients who might obtain long-term benefit from TUIP.

TUIP was comparable to TURP in terms of functional outcomes within the first 12 months after surgery, apart from Qmax that was more significantly improved with resection. ${ }^{2}$ However, TUIP has significantly shorter operative time and hospital stay than TURP. ${ }^{11-14}$ Nevertheless, there is little evidence on long-term effectiveness and there is no clear cutoff prostate size that achieves long-term favourable outcomes after TUIP. Prostate size was found to correlate with BOO 
in patients with a prostate volume $\geq 30 \mathrm{~g}$, a finding which was not seen in patients with smaller prostates. ${ }^{4}$ Therefore, other contributing $\mathrm{BOO}$ pathophysiological factors could play a role, whereas prostate size seems to correlate with TUIP outcomes. Consequently, it would seem logical not only to evaluate the outcome of TUIP using the new era of laser management for infravesical obstruction, but also to determine the predictors of success for this minimally invasive simple procedure.

In the present study, all subjective and objective voiding parameters, including IPSS, QoL, Qmax and PVR, significantly improved within groups. Similar comparable improvement was detected between both groups within the first 12-months after TUIP. However, further follow-up supported the more significant improvement of patients managed for prostate smaller than $30 \mathrm{cc}$ than those with larger prostates. In addition, after a median follow-up of 5.3 years, Group 1 had favourable long-term follow-up in IPSS and Qmax. QoL even deteriorated in comparison with its baseline values in patents with prostates larger than $30 \mathrm{cc}$. These differences were maintained in the multivariate regression model, after correcting for all possible perioperative confounders.

Aho and colleagues found no significant differences between Ho-TUIP and HoLEP for small prostates in IPSS, QoL, and Qmax at any time during the 12-month follow-up. Moreover, both groups showed significant improvements from baseline in these outcome measures. ${ }^{7}$ However, no long-term data were available about the functional outcomes after Ho-TUIP. Only two earlier studies reported a comparable symptomatic benefit of TUIP with TURP which persisted for up to 5 years. ${ }^{3,15}$ Otherwise, meta-analysis and systematic reviews failed to detect improvement in symptom score after TUIP at 12 months compared to TURP. ${ }^{1,2}$ This might be due to the high drop-out rates and the inconsistent patterns of evaluation of effectiveness.

In a randomized prospective study, the objective results were better after TURP than TUIP due to the frequent formation of complex adhesions or synechiae observed within 24 months between the prostatic lobes and the excessive scarring of the incisions in 5/21 patients that further deteriorated the flow rate with time. The comparable Qmax between both groups in the latter study after 60 months could be attributed to the fewer number of evaluable patients after 5 years, in addition to the fact that a quarter of patients needed TURP after TUIP for progressive symptoms. ${ }^{3}$ In a concomitant study, Qmax improvement was maintained above $15 \mathrm{~mL} / \mathrm{sec}$ in $78 \%$ of patients at the most recent follow-up. ${ }^{15}$ This encouraged the authors to conclude that sustainable urodynamic and subjective improvement after bladder neck incision were maintained long term.

In terms of complications, our patients were comparable in the early and late adverse events. Moreover, there was no significant bleeding complication, which is consistent with previous reports. ${ }^{7}$ In contrast, significant bleeding was reported in $4.3 \%$ of patients undergoing TUIP using electrocautery, including the need in $0.9 \%$ of patients for blood transfusion. ${ }^{16}$

The overall re-operation rate in our patients was $11 \%$, which was lower than that previously observed in a metaanalysis of 6 previous studies $(18.4 \%)$, and slightly higher than the $7.2 \%$ re-operation rate reported after TURP. ${ }^{1}$ In a randomized controlled study, despite the small sample size and the short follow-up after holmium TUIP, 20\% reoperation rate has been reported for residual adenoma. ${ }^{7}$ However, 4 of the 5 patients in whom holmium bladder neck incision failed in the latter study had prostate size greater than $30 \mathrm{cc}$, which is consistent with our results. Of interest, re-operation after TUIP for the management of LUTS secondary to BPE was mostly needed after 12 months., ${ }^{3,17}$ This highlights the importance of prolonged follow-up to fully evaluate the reoperation rate after this procedure. The significantly higher re-operation rate for prostate larger than $30 \mathrm{cc}$ in our patients may indicate that the re-operation rate could be improved with appropriate selection of patients with smaller prostates.

The findings of this study highlight the importance of long-term follow-up; our findings also warn clinicians not to be satisfied with 12-month data when evaluating surgical options, particularly minimally invasive procedures.

Overall retrograde ejaculation was detected in $25.6 \%$ of our sexually active men, which was consistent with the $27.6 \%$ reported in a systematic review of randomized controlled trials. ${ }^{1}$ Moreover, a significantly lower risk for retrograde ejaculation was reported in men undergoing TUIP than after TURP $(27.6 \%$ vs. $51.8 \%$, RR 0.54, $p<0.001){ }^{1}$ The $80 \%$ retrograde ejaculation which has been previously reported after Ho-TUIP may be due to the lower number of evaluable patients (12/20) at 12 months. In addition, the number of patients who were able to comment on ejaculation was not mentioned, as described by the authors. ${ }^{7}$

This study is limited by its retrospective nature and the disparity in sample size between both groups. Lack of urodynamic studies might represent another limitation. ${ }^{18}$ Nevertheless, the current cohort presented the long-term outcome available to date for patients undergoing Ho-TUIP and highlighted the impact of prostate size on the outcome of the procedure.

\section{Conclusion}

Ho-TUIP is a durable, safe and efficient procedure to treat BOO secondary to a small-sized prostate. Long-term outcome could be improved and the reoperation rate could be minimized with appropriate selection of cases, with prostate glands no larger than $30 \mathrm{cc}$. 
Elhilali et al.

Competing interests: The authors all declare no competing financial or personal interests.

This paper has been peer-reviewed.

\section{References}

1. Lourenco $T$, Shaw $M$, Fraser $C$, et al. The clinical effectiveness of transurethral incision of the prostate: A systematic review of randomized controlled trials. World J Urol 2010;28:23-32. http://dx.doi. org/10.1007/s00345-009-0496-8

2. Yang $Q$, Peters TJ, Donovan JL, et al. Transurethral incision compared with transurethral resection of the prostate for bladder outlet obstruction: A systematic review and meta-analysis of randomized controlled trials. J Urol 2001;165:1526-32. http://dx.doi.org/10.1016/S0022-5347(05)66342-2

3. Jahnson $S$, Dalen $M$, Gustavsson $G$, et al. Transurethral incision versus resection of the prostate for small to medium benign prostatic hyperplasia. J Urol 1998;81:276-81. http://dx.doi.org/10.1046/i.1464410X.1998.00535.x

4. Li X, Pan J-h, Liu Q-g, et al. Selective transurethral resection of the prostate combined with transurethral incision of the bladder neck for bladder outlet obstruction in patients with small volume benign prostate hyperplasia (BPH): A prospective randomized study. PLOS ONE 2013;8:e63227. http://dx.doi. org/10.1371/journal.pone.0063227

5. Bach T, Muschter R, Sroka R, et al. Laser treatment of benign prostatic obstruction: Basics and physical differences. Eur Urol 2012;61:317-25. http://dx.doi.org/10.1016/i.eururo.2011.10.009

6. Orandi A. Transurethral incision of prostate compared with transurethral resection of prostate in 132 matching cases. J Urol 1987;138:810-5.

7. Aho TF, Gilling PJ, Kennett KM, et al. Holmium laser bladder neck incision versus holmium enucleation of the prostate as outpatient procedures for prostates less than 40 grams: A randomized trial. J Urol 2005;174:210-4. http://dx.doi.org/10.1097/01.ju.0000161610.68204.ee
8. Elshal AM, Elmansy HM, Elhilali MM. Two laser ablation techniques for a prostate less than $60 \mathrm{~mL}$ : Lessons learned 70 months after a randomized controlled trial. Urology 2013;82:416. http://dx.doi. org/10.1016/i.urology.2013.02.074

9. Ruszat R, Seitz M, Wyler SF, et al: Green Light laser vaporization of the prostate: Single-center experience and long-term results after 500 procedures. Eur Urol 2008;54:893-901. http://dx.doi.org/10.1016/i. eururo.2008.04.053

10. Elshal AM, Elkoushy MA, Elmansy HM, et al. Holmium: YAG transurethral incision versus laser photoselective vaporization for benign prostatic hyperplasia in a small prostate. J Urol 2014;191:148-54. http://dx.doi. org/10.1016/i.juro.2013.06.113

11. Nielsen HO. Transurethral prostatotomy versus transurethra prostatectomy in benign prostatic hypertrophy. A prospective randomised study. Br J Urol 1988;61:435-8. http://dx.doi.org/10.1111/j.1464410X.1988.tb06592.x

12. Riehmann $M$, Knes $J M$, Heisey $D$, et al. Transurethral resection versus incision of the prostate: A randomized, prospective study. Urology 1995;45:768-75. http://dx.doi.org/10.1016/S0090-4295(99)80081-8

13. Saporta L, Aridogan IA, Erlich N, et al. Objective and subjective comparison of transurethral resection, transurethral incision and balloon dilatation of the prostate. A prospective study. Eur Urol 1996;29:439-45.

14. Dorflinger T, Jensen FS, Krarup T, et al. Transurethral prostatectomy compared with incision of the prostate in the treatment of prostatism caused by small benign prostate glands. Scand J Urol Nephrol 1992;26:333-8. http://dx.doi.org/10.3109/00365599209181222

15. Neykov KG, Panchev $P$, Georgiev M. Late results after transurethral bladder neck incision. Eur Urol 1998;33:73-8. http://dx.doi.org/10.1159/000019514

16. Orandi A. Transurethral incision of prostate (TUIP): 646 cases in 15 years - a chronological appraisal. $B r$ J Urol 1985;57:703-7. http://dx.doi.org/10.1111/j.1464-410X.1985.tb07036.x

17. Waymont $B$, Ward JP, Perry KC, et al. Long term assessment of 107 patients undergoing bladder neck incision. Br J Urol 1989;64:280-2. http://dx.doi.org/10.1111/i.1464-410X.1989.tb06013.x

18. Gomes $C M$, Nunes RV, Araujo RM, et al. Urodynamic evaluation of patients with lower urinary tract symptoms and small prostate volume. Urol Int 2008;81:129-34. http://dx.doi.org/10.1159/000144049

Correspondence: Dr. Mostafa M. Elhilali, Professor of Urology, McGill University Health Centre, 1001 Boul. Decarie, D05.5327, Montreal, Quebec H4A 3J1; mostafa.elhilal@muhc.mcgill.ca 